\title{
O PROJETO “A MÚSICA DA GENTE”: ENTREVISTA COM CARLOS KATER
}

\author{
Regina Marcia Simão Santos (UNIRIO) * \\ Carlos Kater (USP) **
}

\begin{abstract}
RESUMO
Entrevista inédita com Carlos Kater feita por Regina Marcia S. Santos, abordando as características do projeto "A Música da Gente". São apresentadas aqui informações básicas sobre esse projeto original de criação instrumental coletiva, realizado em escolas públicas da periferia de São Bernardo, pelo qual já passaram mais de 900 crianças (faixa etária de 8 a 11 anos). Vários estudiosos comentaram "A Música da Gente", mas nessa entrevista o seu criador e diretor faz referência particular a alguns dos conceitos, definições e princípios fundamentais que sustentam a proposta do ponto de vista do engajamento dos educadores musicais, face a uma formação humana mais ampla, incluindo, sem exceção, todos os envolvidos na relação de aprendizagem. Estamos aqui diante de um contraponto entre entrevistado e entrevistadora, focado num tema e projeto de alta relevância, do qual emergem reflexões originais valiosas para os profissionais da educação que atuam hoje na formação musical de crianças nas diferentes cidades do Brasil.
\end{abstract}

Palavras-chave: Educação musical. Composição coletiva infantil. Música e formação humana. Papel do educador.

\begin{abstract}
PROJECT “A MÚSICA DA GENTE” (“OUR MUSIC”): INTERVIEW WITH CARLOS KATER

An unpublished interview with Carlos Kater done by Regina Marcia S. Santos, in which he talks about some characteristics of the Project "A Música da Gente" "Our Music"). We present the basic information about this original instrumental collective creation project, carried out in public schools in suburban areas of São Bernardo, which has affected more than 900 children (from 8 to 11 years old). Several scholars have commented on "A Música da Gente", but in this interview its creator and director makes particular reference to some of the concepts, definitions and fundamental principles that support its proposal from the perspective of the engagement of musical educators in relation to a broader human formation, including, without exception, all those involved in the learning relationship. In this interview we are presented with a counterpoint between interviewee and interviewer, and the focus in such important
\end{abstract}

* Doutora em Comunicação. Mestre em Educação e Bacharel em Piano pela Universidade Federal do Rio de Janeiro (UFRJ). Licenciada em Música pela Universidade Federal do Estado do Rio de Janeiro (UNIRIO). Professor Adjunto IV (UNIRIO). Membro do Grupo de Pesquisa Música e Educação Brasileira. E-mail: regina.marcia.simao@gmail.com

** Doutor em Musicologia pela Universidade de Paris IV - Sorbonne. Professor Colaborador do Programa de Pós-Graduação em Música da Escola de Comunicação e Artes da Universidade de São Paulo (ECA/USP). Professor Titular pela Escola de Música da Universidade Federal de Minas Gerais (UFMG). E-mail: carloskater@gmail.com 
project and theme generates many valuable reflections to those education professionals that currently work towards children's musical education in different cities in Brazil. Keywords: Musical education. Kids' collective composition. Music and human formation. Educator's role.

\section{RESUMEN}

\section{EL PROYECTO “A MÚSICA DA GENTE”: ENTREVISTA CON CARLOS KATER}

Entrevista inédita con Carlos Kater hecha por Regina Marcia S. Santos, que abarca las características del proyecto "A Música da Gente" ("Nuestra música"). Se presentan aquí informaciones básicas sobre este proyecto original de creación instrumental colectiva, realizado en escuelas públicas de la periferia de São Bernardo do Campo/ SP, por lo cual ya pasaron más de 900 niños (franja etaria de 8 a 11 años). Varios expertos comentaron “A Música da Gente”, pero en esa entrevista su creador y director hace referencia particular a algunos de los conceptos, definiciones y principios fundamentales que sostienen la propuesta desde el punto de vista del compromiso de los educadores musicales, frente a una formación humana más amplia, incluyendo, sin excepciones, a todos los envueltos en la relación de aprendizaje. Estamos aquí ante un contrapunto entre entrevistado y entrevistadora, enfocado en un tema y proyecto de alta relevancia, de lo cual emergen reflexiones originales valiosas para los profesionales de la educación que actúan hoy en la formación musical de niños en las diferentes ciudades de Brasil.

Palabras clave: Educación musical. Composición colectiva infantil. Música y formación humana. Papel del educador.

\section{Início}

Regina Marcia - Desde que me deparei com o projeto "A Música da Gente", sabia que estava diante de uma proposta inédita, singular, de alta competência musical e profundo comprometimento com valores educacionais cruciais para o nosso tempo. O Carlos Kater musicólogo e compositor abraçava mais uma vez a educação, prática que também compõe os campos de interesse da musicologia. Portanto, é uma grande satisfação para mim entrevistá-lo aqui. Você poderia nos contar como surgiu o projeto "A Música da Gente"?

Carlos Kater - O projeto "A Música da Gente" foi formulado em 2012 e surgiu como resposta a várias necessidades que já estavam presentes em meu trabalho como educador musical há anos. Dentre os períodos mais marcantes desse longo percurso estão quando comecei a trabalhar na FEBEM de São Paulo, em 1975, na coordenação de atividades de cultura e lazer; e desde 1997, quando, junto com uma equipe coordenadora, concebemos o projeto "Música na Escola", realizado pela Secretaria de Estado da Educação de Minas Gerais - um dos primeiros do gênero a ser implantado de maneira sistemática no país. ${ }^{1}$ Dentre essas necessidades, encontram-se a questão relativa ao tipo de repertório musical a ser trabalhado em sala de aula; a importância do engajamento do aluno e do educador no processo de desenvolvimento de sua própria musicalidade; o sentido contemporâneo de propiciar que o ato educativo pela música seja criativo e instigante o suficiente para despertar problemáticas ligadas ao desenvolvimento da pessoa humana.

RM - Um ato educativo-criativo, comprometido com o desenvolvimento da pessoa humana e com uma musicalidade própria a esses sujeitos, sem descuidar do tipo de repertório musical: você pode detalhar um pouco mais essas que me parecem ser as principais características do projeto?

\footnotetext{
1 Esse projeto foi concebido e coordenado por uma equipe composta por Carlos Kater, Rosa Lucia Mares Guia, Betânia Parizzi, Maria Amália Martins, Mateus Braga e José Adolfo Moura.
} 
CK - De fato, temos aí as principais características do "A Música da Gente", embora a mais evidente seja a de promover a criação musical instrumental, orientada para o desenvolvimento da expressão individual e da composição coletiva. Em razão disso, considerei que o uso de objetos sonoros e a construção de instrumentos musicais não convencionais poderia favorecer uma sonoridade especial para o projeto, pois além de mais autêntica e direta, se mostra menos comprometida com os limites técnicos das práticas instrumentais tradicionais (e o uso de bombonas de água de plástico, tubos de PVC, marimba de garrafas d'água etc. representa por si só uma marca musical identificadora do projeto). Com isso, a exploração sonora, o desenvolvimento da musicalidade e a expressão pessoal de cada participante adquirem fluência mediante estratégias lúdicas diversas, sejam jogos sonoros, brinca-

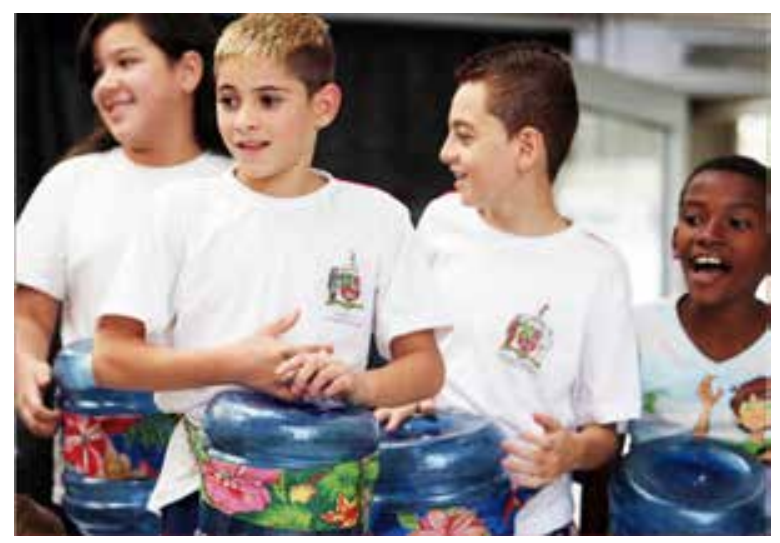

Uso de Garrafões de plástico de água (objetos sonoros). Apresentação musical de uma das turmas no CEU Celso A. Daniel, 2015

$\mathbf{R M}$ - Em cada relato e registro do "A Música da Gente" que pude acompanhar, fica evidente que histórias de vida se potencializam a partir desse projeto. Serve-lhe perfeitamente a afirmativa de Muniz Sodré, quando fala de educação como um projeto ético, aberto à realização humana, voltado para a criação humana: "A educação difere da informação pela radicalidade ética. Ética significa, nesse caso, abrir o horizonte de realização humana. [...] A ética é um horizonte deiras de mão, experimentação instrumental e vocal, improvisação - livre e semidirigida - e, finalmente, a criação de músicas, em diferentes modalidades, estilos e formações. Tudo isto transparece com clareza quando escutamos as composições. Por outro lado, a maioria dos títulos dá uma ideia dos temas imaginados no processo compositivo: Malolucaca, Floresta macacossuada, Arte no barulho, Calango medieval, Que faz bem!, Somos todos misturados, Som que contagia, Banda Luz do Sol, Entendeu? etc. Contudo, entre os propósitos do projeto está também o de não se restringir ao "fazer" apenas - isto é, dar aulas, compor música, interpretar peças, construir instrumentos etc. -, mas de incluir, sempre que possível, o cultivo do "ser". Cheguei a fazer referência a isso num texto intitulado "O que podemos esperar da Educação Musical em projetos de ação social" (KATER, 2004).

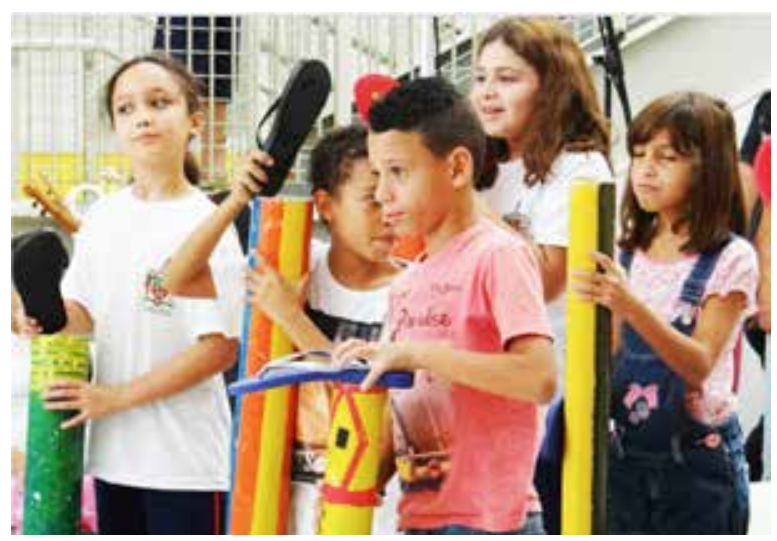

Uso de Tubos Sonoros (instrumentos musicais construídos). Apresentação musical de uma das turmas no CEU Celso A. Daniel, 2015

aberto para a realização humana, para a criação humana" (SODRÉ, 2002, p. 32). Comente sobre as edições do "A Música da Gente". A primeira foi em 2013, correto?

CK - Sim, a primeira edição ocorreu de fevereiro de 2013 a junho de 2014, com cerca de 340 alunos e alunas, de 9 a 10 anos, da escola pública EMEB Arlindo Miguel Teixeira, ${ }^{2}$ em São Bernardo do Campo (SP). Todas as crianças par-

2 EMEB - Escola Municipal de Ensino Básico. 
ticipantes não tinham formação musical anterior e nesse primeiro momento do projeto privilegiei três focos da relação "Som \& Música" e sua apreensão (apreender pela escuta e apreender pelo entendimento). O primeiro foi evidentemente o foco "Criativo", iniciado através de um conjunto de abordagens dedicadas a motivar e dar meio para a expressão das crianças, por um lado, e, por outro, a favorecer o contato com a matéria sonora e com a própria musicalidade dos participantes. Essas abordagens integraram procedimentos de experimentação na produção e na organização dos sons - em conjunto com oportunidades de socialização -, que resultaram na composição de músicas inéditas. O outro foco foi o "Cultural", um espaço privilegiado de conhecimento, de escuta e apreciação de matrizes musicais da tradição brasileira. Entre outras ações, gravamos em estúdio algumas matrizes rítmicas já consagradas (baião, maracatu, jongo etc.) e após propus uma espécie de contraponto feito pelas crianças sobre a gravação, ${ }^{3}$ visando tanto a apropriação dessas matrizes, quanto a sondagem de padrões culturais herdados por elas. E o terceiro foco finalmente foi o "Ecológico", que se ofereceu como zona de percepção, mapeamento e representação das sonoridades da escola e de seu entorno. Resultou dele o conhecimento das especificidades sonoras do espaço interno da instituição e das paisagens sonoras da região. ${ }^{4}$ Uma seleção representativa dessas realizações está registrada no $\mathrm{CD}$, gravado no final de 2013 e lançado em $2014 .^{5}$

RM - E como foi a segunda edição? Você trabalhou da mesma maneira, recorreu a esses mesmos focos?

CK - O trabalho foi semelhante, embora os focos tenham sido um pouco diferentes. A segunda edição se deu de fevereiro de 2015 a junho de 2016, com inúmeros pontos em comum com a primeira edição, ao lado de certas inovações. O

3 A gravação das matrizes rítmicas foi feita pelo percussionista Ari Colares em estúdio e depois sobre elas foram gravadas as interações das crianças.

4 Em especial das aves, como biguás, garças, canários, curiós, sabiás etc. A EMEB Arlindo M. Teixeira se encontra próxima à margem da represa Billings, que é praticamente uma reserva natural, com presença de várias espécies de aves.

5 A Música da Gente (2013). Várias de suas faixas estão disponíveis no Facebook do projeto: $<$ https://www.facebook.com/amusicadagente $>$. fato de termos gravado antes o $\mathrm{CD}$ e realizado um grande número de apresentações nas escolas da região - em eventos públicos da rede de ensino e no grande auditório do CENFORPE ${ }^{6}$ - conferiu maior credibilidade à proposta, o que facilitou bastante o acolhimento do projeto na nova instituição onde ocorreu. Essa edição foi realizada no CEU Celso Augusto Daniel, ${ }^{7}$ também em São Bernardo do Campo (SP), porém com 360 crianças, divididas em 14 turmas, na faixa etária de 8 a 11 anos. Como na primeira edição, nenhuma delas possuía formação musical anterior e trabalhamos à razão de dois encontros por semana, 50 minutos cada. Aqui, os eixos centrais adotados foram um pouco diferentes e incidiram na relação "Música \& Formação". Contemplaram a escuta, a vivência, a experimentação e a criação musical, com ênfase na representação da palheta estética e incorporaram uma estratégia prática desafiadora: possibilitar às crianças o acesso a seu mundo interior, o contato consigo. Foram três os eixos orientadores: o central, como não poderia deixar de ser, foi o "Artístico-Criativo", representado pela composição e interpretação de músicas inéditas pelas próprias crianças. $\mathrm{O}$ segundo, $\mathrm{O}$ "Social-Interativo e Colaborativo", que, entre suas particularidades, contou com a participação de músicos convidados, todos representando um personagem específico. ${ }^{8}$ E finalmente, o eixo "Estético-Cultural", que promoveu a vivência de estilos e estéticas musicais ampliados, como o Maculelê, Maracatu, Samba, mas também Rock, Música Eletrônica, Músicas do Mundo etc., ao lado de diversas abordagens conceituais contemporâneas ("Música Vida", "Música dos Dedos", "Música dos Pés", "Música dos Objetos").

6 CENFORPE - Centro de Formação dos Profissionais da Educação. No facebook há igualmente registros visuais e sonoros de várias dessas apresentações.

7 CEU - Centro Educacional Unificado.

8 Participaram como músicos convidados: Claudia Freixedas como "Dona Melódia" (flautas), Gabriel Levy como "Seu Sanfônico" (sanfona), Leandro de César como "Leandrock" (guitarra elétrica), Max Schenkman como "Dr.Som" (instrumentos inventados) e o duo Camila Fuchs como "Musique \& Letronik" (música eletrônica), duo londrino formado por Camila Laborde e Daniel Hermann, que vieram fazer residência por um mês e meio no projeto. 


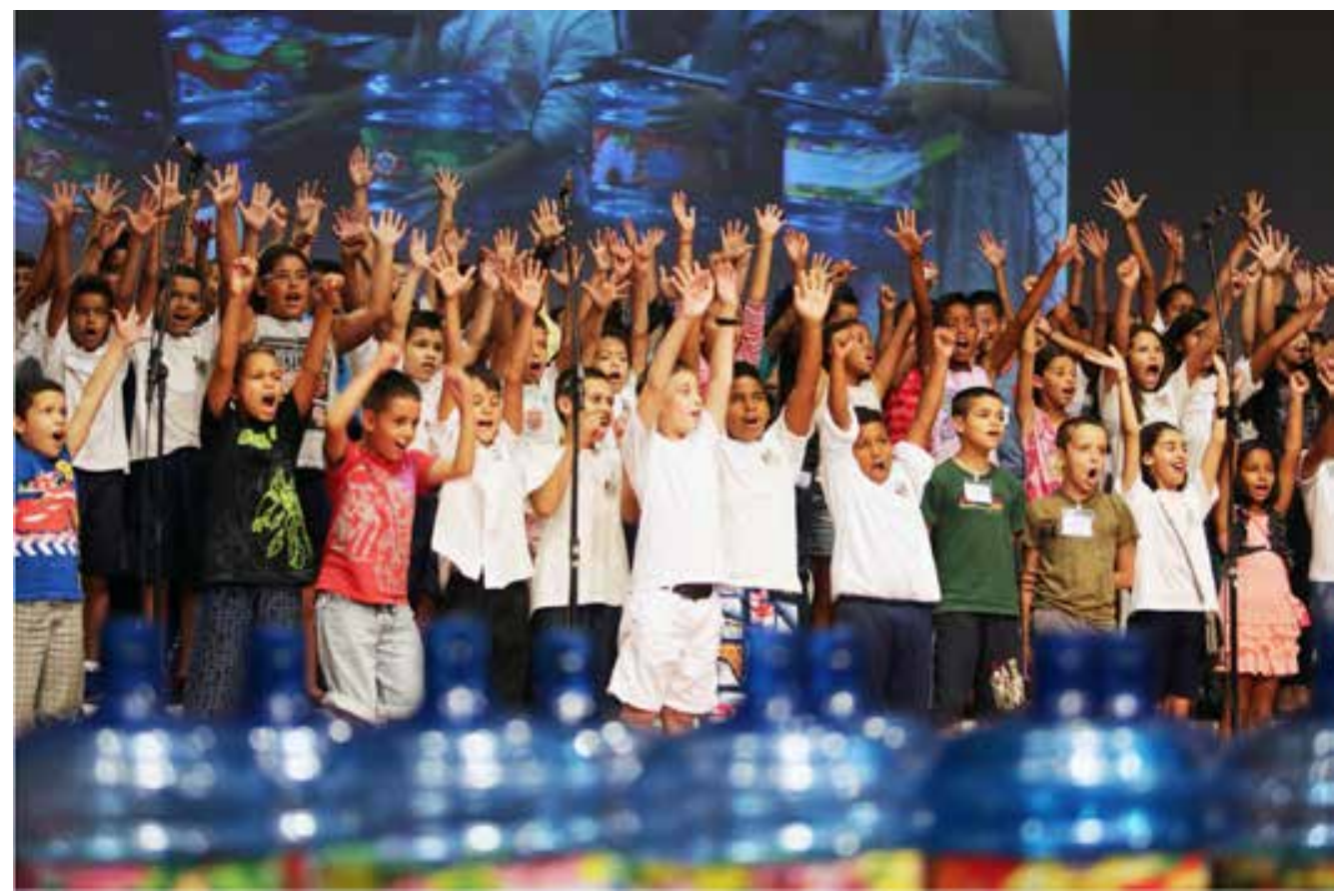

Parte final de uma apresentação musical no auditório do CENFORPE, em S.Bernardo do Campo, reunindo diversas turmas do período matutino (2014). No fundo do palco, projeção de imagens do histórico de criação das músicas, servindo de elemento de cenário e ao mesmo tempo apresentando as diversas fases do processo que gerou os resultados apresentados.

RM - Para quem acompanha os registros do projeto fica evidente que "A Música da Gente" passeia por territórios da experimentação sonora, acolhe as discursividades e a imprevisibilidade inerente à ludicidade, as manifestações da cultura e as expressões musicais dessa gente miúda (pequenos compositores). Poderíamos considerar que "música interior" e "música exterior" sejam preocupações sistemáticas do projeto?

CK - Você pontua bem essas distinções feitas no projeto entre "música interior" e "música exterior”. De fato, não há, a meu ver, música que possamos validar nos processos educativo-musicais quando originada exclusivamente do "exterior" ou do "interior", embora a imensa maioria dos projetos musicais privilegiem a primeira dessas possibilidades. Mesmo com as valiosas contribuições que se sucederam dos movimentos modernistas do início do século XX e de John Cage aos "métodos ativos" em educação musical, entre inúmeras outras contribuições da música contemporânea, não temos ainda nos dias atuais compreendido e sobretudo praticado suficientemente a distinção entre elas: a "música exterior", essa música social e musicológica, por assim dizer, a música dita com "m" maiúsculo - que nos chega por força das definições históricas e culturais -, e a "música interior", aquela que adquire existência junto aos ouvidos pela curiosidade de nosso espirito, pela necessidade de nossa própria escuta (que vale lembrar, vem se construindo desde tempos remotos e ancestrais). Na primeira incide a apropriação da tradição, a informação e a educação; tudo o que nos precede e representa o patrimônio constituído de conquistas e descobertas, com o que possa haver aqui de positivo e negativo (o peso das instituições que em geral se impõem sobre nossas ações e durante períodos de nossa vida falam através de nossas vozes, por exemplo). Na segunda, a "música interior", a dimensão da liberdade e da experimentação, da originalidade e da criação (que é a ênfase assumida pelo projeto). São essas duas grandes vertentes que basicamente constroem o sentido de música no ser humano, 
integrando no desenvolvimento de sua musicalidade o mundo interior e o mundo exterior, uma vez mais... o "eu" e o "outro". A meu ver, essa é, em síntese, a meta que merece ser perseguida - no equilíbrio desejado - pela educação musical nas salas de aula das escolas de hoje. Comentei um pouco sobre o papel fundamental desempenhado por essa relação no processo educativo no artigo “Por que Música na Escola?” (KATER, 2012).

RM - Importantíssimo esse seu destaque ao equilíbrio entre as duas vertentes que compõem o sentido de música no ser humano! Muitas vezes o educador se sente mais confortável e seguro no exercício da música com "m" maiúsculo, fazendo apenas eventuais incursões no que você chamou de segunda vertente - vertente da experimentação e invenção -, ora num exercício de laissez-faire, ora visando o treinamento dos saberes tomados da primeira. A articulação entre essas duas vertentes é vital no projeto educativo. Mas você falou também em salas de aula. Podemos pensar o projeto como um conjunto de aulas de música? Ou, a seu ver, isso não seria apropriado para definir "A Música da Gente"?

CK - Existem alguns temas antigos na educação musical que demonstram sua importância pela pregnância que ainda hoje têm na realidade de inúmeros centros de ensino e no exercício de muitos professores, no Brasil e no exterior. Entre eles está, justamente, o desequilíbrio entre teoria e prática, ou entre o "discurso sobre música" e a "vivência da experiência musical" propriamente dita. No projeto, as propostas de trabalho se dirigem preponderantemente à vivência musical e é no bojo de seu processo que trabalhamos as informações relativas à música, à medida que os problemas ou questões vão surgindo, de acordo com as necessidades... (necessidade, mãe de todas as invenções!). Considero que o desafio atual para os educadores e educadoras musicais é o de trabalhar a música de maneira mais completa, sem "glissar" e se instalar, sem muito critério, num ou noutro desses dois extremos: a fala sobre música, com informações de superfície, cercadas por nomes, datas e belas imagens, em detrimento da vivência e do contato com a matéria sonora viva; ou, por outro lado, a prática da música, com condução fortemente dirigida, abstraída de considerações, reflexão e apreciação crítica, restrita a exercícios de reprodução vocal ou instrumental. Nesse sentido, o projeto, ao invés de "dar aulas" de música ou sobre música, promove, como disse, a sua "vivência criativa". E há aqui, vizinha à questão de balanceamento entre "prática" e "teoria", uma outra... a do ensinar e a do apreender, pois todas as vezes em que o educador se identifica exclusivamente com a função do "professor que dá aulas", ele se veste de "transmissor de informações" e assume posição de excessiva verticalidade em relação ao grupo, no papel estreito de "ensinante". E esse radicalismo, que já não é bom para os alunos, bem pior se mostra ainda para o próprio educador, que com frequência demonstra apatia, falta de motivação e criatividade em conceber ou realizar as suas aulas, pouco engajamento com as questões pedagógicas, excessiva lamentação pela falta de condições de trabalho e, sobretudo, reclamação constante sobre o desinteresse dos alunos por suas próprias aulas!

RM - De fato, só há saber vindo da experiência, da atitude inquieta diante do mundo, de ser afetado por algo que nos força a pensar. Ao se afastar da cultura escolar centrada na pedagogia transmissiva, com a figura do professor que vai ali "dar aula" (passar informações, "ensignar"), você pensa uma aula-composição tecida no emaranhado de linhas trazidas por esses sujeitos da experiência. É preciso reinventar essa "aula" e parece que é essa a sua tônica. Eu mesma gostaria que pudéssemos sempre pensar em aula como acontecimento, experiência que nos atravessa, nos marca, nos leva a pensar, produz aumento de potência de vida. O que o projeto propõe quanto a isso?

CK - Desde o início do projeto, busco substituir o "ensinar" pelo "aprender", música e o que mais for possível. E essa divisa serve para todos sem exceção, seja a equipe de trabalho, sejam os alunos e seus professores... "aprender" e "aprender a apreender". O fato de o objetivo do projeto ser a composição de músicas inéditas (portanto conceber e dar vida àquilo que ainda não existe no mundo exterior) engaja todos os participantes num processo dinâmico, por vezes de alta entropia, cujas bases iniciais podemos conhecer, mas jamais prever onde exatamente desembocarão. E o mais sensato nessas situa- 
ções é dar meios e condições para aprendermos ao vivo sobre o processo inventivo em si, por consequência, apreendendo, pela observação e pela escuta, algo também do mundo, nos relacionando com ele e todos do grupo de maneira intensa, autêntica, inovada. E não há garantia de que essa apreensão do mundo por uma "escuta desperta" ocorra para uma criança, a rigor, nem mesmo para um adulto! No entanto, acredito que pela exploração de seus limites através da música, pela nomeação do que emana por força e beleza desse vivido, dos novos contados consigo e com o grupo, damos melhores condições para que ela apreenda também algo mais essencial, ligado à sua própria essência. E, no seu tempo, ao longo de sua vida, ela poderá talvez perceber o quanto ter vivido experiências significativas na escola, e em sua história, foi importante, o quanto hoje isso é valioso. Essa é a dimensão expandida da educação, que não podemos perder de vista nos atos do presente. Por isso ser parte fundamental do processo educativo o dar oportunidades, dispondo, de forma estimulante, um campo amplo, significativo e coerente de alternativas que cada pessoa, a seu tempo e a sua maneira, poderá ou não apreender, dar uso, conferir significado.

RM - Estamos diante de uma pedagogia aberta, de currículos flexíveis, aos quais a literatura se refere como dançantes, moventes, rizomáticos, mapas que são da ordem da experimentação, exigindo profissionais com um perfil diferente do de um "ensinante" de um programa pré-ordenado a ser aplicado. No caso do projeto, como é esse processo de trabalho e o que ele requer em termos de formação dos sujeitos da educação?

$\mathbf{C K}$ - Antes de começar os encontros com as crianças, realizo o mesmo com a equipe que atua no projeto. Por cerca de 2 meses, entre reuniões de grupo e individuais, tratamos os princípios e linhas diretivas que nortearão o processo e vivenciamos um conjunto de atividades, para somente após isso irmos a campo na escola. Utilizo um conjunto de estratégias lúdico-musicais alinhadas a um processo que se desenrola dos primeiros contatos com a música até a criação musical propriamente dita. Desde o início optei por trabalhar com um roteiro, mais próximo de um mapa de percurso do que de um projeto ou programa propriamente dito. Instaurar e acompanhar as diversas fases de um processo criativo é de certa forma testemunhar e lidar com o próprio surgimento da vida. Sua sutileza e sua complexidade se tornam ainda maiores quando esses processos envolvem muitas pessoas (embora divididas em turmas, são sempre 360 crianças!), cuja condução se dá por uma equipe, que precisa ser formada e supervisionada para manter - além da necessária sintonia interna - uma coerência efetiva com os princípios da proposta junto a todos os envolvidos (crianças, seus professores, coordenação pedagógica e direção da instituição).

$\mathbf{R M}$ - Você me permite um parêntesis? Ao falar de ter um roteiro, mais próximo de um mapa de percurso do que de um programa, conectei essa ideia diretamente com um trecho do livro $O$ que é a filosofia?, de Deleuze e Guattari, quando diz que a forma "se constrói na medida em que a obra avança” (DELEUZE; GUATTARI, 1997, p. 243). Não se parte do vazio, assim como também não se prescreve uma rota. Mas há sempre um plano de orientação (que não é para ser aplicado), já que temos que lidar com uma situação aberta, num mundo imanente, conforme lembra Tomaz Tadeu da Silva. Em linhas gerais, como se dá o processo desse ato educativo criativo, de que grandes momentos ele se constitui?

CK - Parto, de fato, do princípio de que toda pessoa, criança ou não, sabe sempre alguma coisa. Não existe ninguém que "não saiba nada", que seja um "vaso vazio" no qual o professor versa aquilo que considera, no seu tempo-espaço particular, informações musicais ou de qualquer outra ordem. Compreender que uma criança não é uma "matriz em branco" significa reconhecer que ela traz consigo heranças culturais e conhecimentos de várias naturezas, bem como padrões de funcionamento que moldam o seu comportamento e determinam o seu desenvolvimento, presente e futuro. Em vista disso, o processo se inicia por uma fase de "Musicalização", contendo vivências de naturezas e objetivos bem diversificados, que permite sondar quem é esse "ser que está sendo", seus potenciais e limites, expressivos e musicais (timidez, ansiedade, menos valia, jogos de controle ou liderança etc.). A partir de um dado momento, segue-se, em paralelo, uma fase que 
chamo genericamente de "Integradora", quando é feita a montagem de diversificadas formações de grupo (solo, duos, trios e até grupo inteiro), verificando o equilíbrio de trocas, estabelecendo referenciais de comportamento, apresentando os protocolos de trabalho etc. É aqui que se definem procedimentos de relacionamento e socialização da turma, em vista dos propósitos do projeto. Os jogos de musicalização passam a contemplar progressivamente atividades lúdicas com maior grau de imprecisão e indeterminação, nas quais as crianças são levadas a se posicionar, argumentar e tomar decisões. Esta é a fase de "Improvisação", que pouco a pouco enfatiza as explorações sonoras, experimentações em geral, situações abertas, de espontaneidade, de exposição e de risco. Desde aqui, então, se transita para a "Criação musical", quando em conjunto são abordados princípios de construção, concepções formais, projetos de organização, jogos de contraste e equilíbrio, planos sonoros e a sempre incentivada busca do "novo", do impensável, inescutado, inimaginado até então. Vale observar que os resultados obtidos ao final das atividades lúdicas - improvisações ou criações musicais são, como "produto", tão importantes quanto o "processo" que lhes deu origem. E se hoje, apesar de quase ninguém mais discordar da importância de ambos (processo e produto) - o que em nível de entendimento parece "indiscutível" -, na maioria das vezes, no entanto, manter essa "dupla" importância na prática mostra-se uma tarefa plena de desafios quase insuperáveis. Sobretudo quando o educador deve sustentar um equilíbrio saudável de participação de mais de 30 crianças em classe ao longo de 10 meses, mantendo-se atento a tudo o que se passa durante o encontro e praticando o desapego e a desidentificação diante de determinadas situações que o implicam diretamente como pessoa (duas das qualidades fundamentais decorrentes do trabalho sobre si, por parte desse profissional).

RM - Conversamos recentemente sobre esse profissional de "mochila cheia" ou de "mochila vazia" para desempenhar seu papel nessa complexa relação dos sujeitos da educação, e quiçá nesse ato educativo criativo. Quem pode atuar assim? Que dimensões assegurar no perfil desse profissional para condução de um trabalho que se faz com os "outros" e na diferença?

CK - De fato, necessitamos de um profissional preparado, que tenha espectro de atuação mais amplo e - enquanto educador musical ou músico-educador - seja também uma pessoa melhor cuidada, isto é, alguém que compreenda a importância de se conhecer melhor e experimente um trabalho sobre si, sobre a sua própria pessoa, como insisto. É sabido que todo processo de criação musical implica em descoberta, nomeação, expressão e novas formulações; compete a esse profissional instaurar o espaço no qual todos os participantes poderão observar um som nascer pelas mãos e desejo de alguém, ser variado, acrescentado ou transformado pela imaginação de outro e assim, paulatinamente, de modulação em modulação, escutar o surgimento de cada música, com a vida particular que cada música tem. Mas para escutar um som vibrando, ouvir uma música soando e perceber a vida se movendo dessa forma, é necessário parar e silenciar um pouco internamente. Fora disso não há meio possível de acolher as coisas e as pessoas como são. E cabe a esse profissional propiciar que as crianças também penetrem neste espaço diferenciado - situado um "palmo acima do chão" -, onde as diferenças com os "outros" não atrapalham tanto, nem criam de fato maiores problemas, mas ao contrário... "aquilo" que somos, com nossas particularidades e diferenças, se torna justamente "aquilo" que a vida de todos enriquece e dinamiza.

RM - Protagonismo do sujeito aprendente. Revitalização do sujeito educador. Soerguimento da pessoa humana. Temos muitos intercessores conosco, nesse projeto de escola, de Paulo Freire a Antonio Nóvoa, Koellreutter e tantos outros, mas continuamos ainda aproveitando pouco as oportunidades...

$\mathbf{C K}$ - Apesar de tantas informações e inovações a que temos acesso hoje, ainda nos deparamos com um excessivo desperdício de oportunidades de formação, sobretudo da pessoa do aluno e do próprio professor ou educador musical, o que é a meu ver lamentável. Compreendemos a importância de uma formação técnica, mas carecem alternativas educativas capazes de impulsionar as crianças para além de sua condição de simples "alunos de classe", "alunos de escola", "alunos de música". 
É possível, porém, fazer diferente e conjugar em nosso trabalho a dimensão técnico-musical com aprimoramento humano. E os educadores e educadoras musicais contemporâneos podem aproveitar o exercício de sua profissão para favorecer esse trabalho de desenvolvimento do conhecimento, de aprimoramento pessoal, de exercício criativo face aos limites existentes, porém com uma condição... com a condição de vivenciarem antes em si próprios, o que se propõem a trabalhar junto ao "outro". De que maneira? Cada qual observando-se, de maneira justa, como age na prática - adentrando suas "cavernas" e reconhecendo sinceramente as suas "sombras" -, para depois então atuar, com a coerência possível, no mundo de fora, procurando auxiliar aqueles com quem trabalha a trilhar os seus próprios caminhos. Falamos com frequência em respeito, tolerância, criatividade, qualidade de vida, cultivo da sensibilidade, desenvolvimento pessoal, autonomia, diversidade e tantas outras belas palavras mais... Entretanto, muito pouco temos visto quanto à prática efetiva desses conceitos, dentro das salas de aula e fora delas também! O discurso sobre a música e sobre a vida parece satisfazer as demandas imediatas da realidade, bem como a imagem confortante e asseguradora que tantas instituições e educadores ainda têm de si. O "século XXI", tão esperado, parece chegar muito lentamente...

$\mathbf{R M}$ - Vivenciar em si próprio aquilo que nos propomos a trabalhar junto ao outro... Estamos diante de um convite a uma viagem-cartografia, a ser feita por educandos e educadores, todos eles aprendizes, experimentando o mundo, num mapa aberto, onde inevitavelmente reside uma parcela de certeza e também de hesitação, num trabalho investigativo que é feito com e não sobre ou para o outro, como dizia Paulo Freire.

CK - Ainda "derrapamos" nesses lugares comuns do pensamento, sem realmente construir alternativas eficientes para incluir na vida vivida tudo o que atribuímos valor na vida pensada, na vida escrita, na vida falada. Parece que ainda nos conhecemos muito pouco... Todos os aspectos que mencionei acima - acrescidos de outros mais, como a postura frente a desafios, a coragem do risco, a liberdade de experimentar etc. -, apesar de fazerem parte da formação dinâmica de todo e qualquer ser humano, muito raramente estão presentes na realidade das escolas e na vida dos profissionais da educação. Falta muito para substituirmos o "aprender", redundante e repetitivo - visando a memorização de informações - pelo “apreender", próprio do captar, apropriar, atribuir significado e tomar consciência, características de formação humana tão reivindicadas contemporaneamente, a todas as instituições de ensino, professores e educadores. E quando falamos atualmente dos problemas de disciplina, alheamento, indiferentismo e violência, que proliferam pelas escolas do país afora - que são eles precisamente da ordem desses conceitos e aspectos acima -, estamos apenas nos referindo à "força das águas do rio que transbordam as margens destruindo cidades" e quase nada compreendendo e, muito menos ainda, propondo na educação para atenuar a violência dessas mesmas margens que aprisionam as águas do rio, como diria Brecht.

RM - Não descartamos a formação técnico-profissional, mas ela parece não dar conta dessa outra educação possível e necessária, cujo foco está na pessoa humana e cujo caminho é o da criação. Koellreutter (1997a, p. 56) diz que "é somente na medida em que o nosso espírito for criador que fazemos experiências". Estamos, portanto, chamando ao diálogo e à reflexão os centros de formação existentes. Que sujeitos estão os centros de formação entregando para o mundo da escola? Qual é a sua visão sobre isso?

CK - Podemos bem falar sobre os atributos do profissional, seja ele Professor de Música ou Educador Musical; outra coisa, porém, bem diferente, é a realidade objetiva de sua formação. A meu ver, há necessidade de um preparo não necessariamente de maior duração, mas de maior consistência do educador musical, que o forme para além das perspectivas restritas de atuação técnico-profissional calcadas em concepções, em geral, pouco adequadas para as múltiplas "realidades brasileiras" que existem em nosso país. Há de fato muita complexidade no que vivemos e as instituições de maneira geral lidam com grandes dificuldades, apesar da competência de muitos de seus professores. No entanto, não penso que esses centros de formação estejam conseguindo acompanhar a velocidade dessas "realidades em movi- 
mento" e suas transformações sociais, não dando conta, assim, de prepararem profissionais para as diferentes naturezas de demanda da atualidade, afora atuação nas escolas, também em ONGs, espaços de reclusão, de saúde, asilos, casas de juventude, creches etc. Não há nem mesmo clareza suficiente na distinção entre "professor de música" e "educador musical" ou "músico-educador" (que é o perfil dos membros de minha equipe), tal como esses termos são normalmente utilizados, dentro e fora das academias. Muito embora as atuações desses profissionais se recobrem por momentos, não é conveniente tomá-las como equivalentes, muito menos sinônimos, como em geral se faz, lembrando sempre, porém, da importância social que todos eles possuem. Distinguindo suas atuações é que parece ser possível destacar as metas distintas que visam; se o primeiro persegue, no âmbito da relação de ensino-aprendizagem, a transmissão de conteúdos e contempla a formação musical, para o educador musical a concepção é diferente, e abarca o que falei antes... vem ao palco das atenções a pessoa do aluno, seu desenvolvimento pessoal e musical, seu protagonismo. Em outras palavras, quando num processo educativo musical o professor se transforma em educador, inverte-se a polaridade de uma formação para a música por uma formação pela música, e isto torna possível aos alunos inscreverem-se então num espaço de construção do sujeito, no qual estratégias dinâmicas de aprendizado (de natureza lúdica e criativa, por exemplo) permitem um desaprisionamento individual que favorece a apreensão da questão da identidade e da alteridade, fundamentos do desenvolvimento humano. Esse é justamente o espaço no qual os saberes pessoais podem dialogar com os saberes consagrados, onde os "saberes induzidos" podem fazer contraponto com os "saberes construídos". E é esta a natureza de Educação Musical que a meu ver merece ser trabalhada hoje nas escolas, integrando também teoria e prática, análise e síntese, tradição e inovação, conferindo à música o seu sentido maior, formador, socializador, inclusivo, transcendente. Porém, vale reiterar novamente... desde que esse educador ou educadora musical se proponha a trabalhar seriamente antes, em si e na prática, o que tem a intenção de trabalhar junto ao outro.
RM - Assunto para outras tantas conversas: professor de música, educador musical e músico-educador parecem não ser equivalentes. Considerando esse conjunto de valores (protagonismo, alteridade, subjetivação...) e o espírito criador como condição de construção do conhecimento, você poderia falar das criações musicais? O que a seu ver são essas músicas compostas pelas crianças?

CK - Nunca é demais insistir que a composição musical promovida pelo projeto não visa a mesma dimensão de arte perseguida pelas obras musicais adultas, inseridas nas ordens estéticas do dia. Bem diferente disso, temos aqui composições que refletem na superfície processos internos em construção, espécie de receptáculos que integram emoções e entendimentos vivos, ativos, moventes. São "músicas-criança", captadas num dado instante de sua construção, que espontaneamente não possuem início nem fim definidos. São instâncias pré-figurativas, emergências que afloram no gesto e no ar, na escuta e no olhar, nas somas de fazeres, de tentativas, de experiências, mediante atitudes lúdicas, no que chamamos "brincar", esse experimentar-explorar visceral de onde germina o inusitado e o extraordinário. Aquilo que vive no homem e faz dele não apenas o homem que é, mas aquele que ele pode vir a ser (Koellreutter se referia para isso ao "espírito criador", o que me parece acertado). São criações que surgem de um nada aparente, agregam-se num espaço-tempo até então ausente e de maneira progressiva vão tecendo significados pessoais de valor social. Mescladas por instantes de calma e turbulência, paz e conflito, incertezas e afirmações, perdas e achados, imposições e submissões... essas músicas carregam igualmente muitas das grandezas e das pequenezas humanas do dia a dia (ciúme, inveja, orgulho, preguiça, prepotência, mau humor...), embora acabem no final por se constituir criativamente bem acima das expectativas infantis cotidianas.

$\mathbf{R M}$ - Retomando tudo que conversamos até aqui, para mim ficam alguns principais pontos a desafiar os educadores em seus projetos. "A Música da Gente" é lugar da produção de formas culturais próprias, de uma poética infantil produzida em meio a objetos, tecnologias e pessoas. É, ainda, espaço de convivência e fazer coletivo, de 
ser afetado por materiais e afetá-los com recortes e escutas, com criações e manipulações de sons, e com a produção de sentidos. É lugar do jogo imaginativo imbricado a convenções musicais intuídas e jogos de regras combinadas no grupo. É lugar de uma cultura lúdica, numa prática de prazer, conhecimento, diversão, encantamento, espanto... Pode não ser uma aula, ou ser uma aula aberta, mas é lugar de processos de formação e atos educativos produzidos por sujeitos cartógrafos. Há muitos sentidos operando aqui!

CK - Uma das metas centrais visadas pelo "A Música da Gente" consiste em propiciar aos participantes o protagonismo face a uma música viva e original, criada por eles mesmos, em sintonia com o seu momento de vida, de acordo com as reais necessidades expressivas e possibilidades de seu desenvolvimento pessoal. E há algo profundamente comovente quando vemos uma criança mergulhada no processo de improvisação ou criação, quando percebemos seu empenho em superar um limite que se coloca e a tolhe, e ela passa então a buscar dar direção ao seu impulso expressivo, que pouco a pouco, sinuosamente, desbrava e acaba por encontrar um caminho próprio. Percebemos aí não apenas alguém ampliando suas fronteiras ou dominando algo, mas a dupla face do processo inventivo: um ser humano construindo e dirigindo sua expressão no mundo exterior ao mesmo tempo em que essa construção e suas direções geram trilhas no seu interior. O que descobre ou inventa, apreende e incorpora para em seguida, então, pôr em prática, transcender e ir além. Disso que se faz e forma, simultaneamente fora e dentro de si, a que chamamos experiência - aliás, bem distinto de experimento - é que se constrói o ser de cada um. Todo ato criativo é uma resposta dinâmica que damos a algo, a algum desafio ou questão, nem sempre claramente formulados. Criar é, nesse sentido, também uma oportunidade de ampliar o "eu consciente". Quando uma criança percebe o sentido daquilo que faz musicalmente, é a sua própria vida que se preenche de sentido e a profundidade que há nisso se evidencia quando nos lembramos de que - como adultos e não apenas como crianças - nós só existimos realmente no tempo presente, tempo que se abre, aprofunda e expande quando estamos mergulhados na experiência criativa.
RM - Entendo que essas composições têm funções específicas. Poderia falar um pouco mais sobre isso?

CK - De fato, se permanecermos na lógica adulta habitual, que opera com base em avaliações criteriosas, rigor crítico, comparações e análises detalhadas etc., não ouviremos, nos resultados musicais das crianças, composições inteiramente inventivas, contendo propostas de organização inovadoras, formas ousadas, rítmicas inusitadas ou ainda... a melhor música do mundo! Não, a ótica a ser adotada aqui é outra, diferente, e possibilitará a quem tiver ouvidos escutar outros mundos da música, da rítmica e das formas, através da ousadia de entendimentos e dos sentimentos espontâneos (ainda, nos seus 8 a 11 anos, não excessivamente formatados pela cultura e pela educação), que, num todo original, tudo incorpora, integra, supera e vai além, como disse. É importante também considerar que essas composições cumprem outras funções importantes: cada uma delas, apesar da aparência simples e singela, recepciona e integra os mais diversos tipos de imaginário sonoro, do simples ao complexo, do livre ao organizado, das autenticidades sutis aos padrões fixos e pré-concebidos. À sua maneira, essas criações representam um espaço de aceitação, inclusão e acolhimento para cada criança. A música minha, a sua, a dele e a dela, é a música da gente. Um espaço especial construído em conjunto, que, apesar de momentos de tensão e conflito - algumas vezes mesmo de ruptura -, acaba por incluir um a um dos participantes, com suas qualidades e limites, positividades e negatividades. Dessa forma, em maior plenitude e sinceridade, instaura-se como gerador de felicidade e penso que seja essa a razão de ouvirmos com tanta frequência crianças dizerem: "Criar me deixa feliz!"

RM - Fala-se muito da ludicidade, do brincar, mas também da interferência do "professor", do adulto nessa experimentação. Qual é a dose? Em que consistiria essa intervenção do adulto na experimentação e processo composicional da criança no projeto "A Música da Gente"?

CK - Não é papel do educador no projeto compor, como adulto, para as crianças ou como educador compor no lugar delas, nem tampouco "conduzir a composição", de maneira a fazer delas a sua força ou ferramenta de trabalho, concreti- 
zando o seu próprio imaginário! Por outro lado, não faz igualmente sentido que o educador se "abandone" de si próprio, transformando-se em público, simples ouvinte ou o irreal "observador imparcial" de seus alunos, durante o processo criativo. O desafio é balizar o processo, "auscultando" atentamente tudo e distinguindo os momentos onde deve agir, interferindo ou não, de qual melhor maneira; quando será necessário motivar a continuidade de um processo ou, ao contrário, simplesmente se sentar diante do "abismo", do vazio de ideias e aguardar as definições do grupo... Todos esses são instantes decisivos que de maneira alguma podem ser ignorados, evitados ou abortados, e nos quais a crítica inadequada e o julgamento de desempenho dos participantes, por parte do educador, devem ceder lugar à reflexão, ao respeito, ao diálogo e à busca de novos entendimentos. Por isso é que se espera daquele que acompanha o processo criativo que não acredite em tudo o que ouve, em tudo o que pensa ou em tudo o que vê. Ao contrário, que ele procure se questionar e institua o questionamento junto aos participantes, para que todos possam enxergar "abismos nos lugares comuns" (cada qual a sua maneira). Essa é a postura que torna possível a construção de uma instância interior, chamada "eu observador", que por consequência amplia o "eu consciente", a partir de onde se pode falar em desenvolvimento pessoal. Mas é igualmente uma forma de dizer... procure manter-se aberto, curioso e corajoso naquele espaço, que o obriga a suspender as suas projeções e a entrar em contato menos intermediado com o que ganha forma diante de você. É justamente essa escuta, pensamento e olhar mais livres e relativizados - menos impregnados de pré-conceitos, de pré-julgamentos e de crítica excessiva - por parte do educador, que permitirá à criança um desenvolvimento adequado (com maior fluência e liberdade), apresentando-se ao mundo musicalmente de forma original e pessoalmente sem tantas das marcas impróprias impostas pela projeção dos adultos.

$\mathbf{R M}$ - Em que se constitui, a seu ver, o ineditismo no projeto "A Música da Gente"?

CK - Falamos um pouco sobre isso, mas há algo que gostaria de acrescentar. Entre as intenções do "A Música da Gente" está a de buscar sintonia com as proposições de tempo e espaço onde ocorre, por um lado, abraçando a contemporaneidade e conjugando características do passado e do presente, bem como respeitando as expectativas e particularidades culturais de seus participantes. Com isso persegue, em conjunto com a criação de músicas, um alvo de transformação social particular, que é o de des-confinar os alunos da condição de "consumidores" musicais, culturais e de tantas ordens mais. Ao invés disso, a ideia é ampliar o seu papel de participação ativa enquanto "Prossumidores" (como definiu Alvin Toffler), produzindo para o seu próprio consumo. No entanto, penso que devemos ir além desse princípio, alcançando novos diálogos com a comunidade e a sociedade. Assim, busco sempre que possível propor a diferentes professores (de educação física, artes visuais, teatro, dança...) que utilizem as músicas compostas no projeto em suas respectivas aulas, atividades ou mostras públicas, ampliando suas funções, assegurando uma maior inserção na realidade. Acredito que essas músicas, além de serem escutáveis e reinterpretáveis, como quaisquer outras, podem ainda ser dançadas, coreografadas, servir de trilha para teatro e contação de histórias, recurso para expressão corporal e jogos corporais com bola, arco e fitas etc. Dessa forma, as composições não se limitam ao palco nem ao calendário civil ou religioso das instituições, mas ocupam salas, quadras, pátios, corredores, exercendo usos e funções muito diversificados, atendendo demandas existentes na própria e em outras escolas, demandas aliás nem sempre claramente percebidas. Há aqui também novas perspectivas a serem vislumbradas, outras funções sociais a serem desempenhadas, uma cultura mais contemporânea a ser implantada.

RM - Para encerrarmos essa entrevista, pergunto: o que seria desejável para uma educação musical hoje?

CK - Eis uma pergunta breve que pode render horas de reflexão e conversa! Com todos os conhecimentos a que temos acesso atualmente, acredito que somos capazes de propiciar uma educação musical inventiva, de qualidade e rica de significados, em nível de processos e produtos. No entanto, são as abordagens ampliadas - que chamo de integradoras, com foco no humano - que, a meu 
ver, possuem melhores condições de fazer interagir processos criativos e procedimentos educativos, beneficiando todos os envolvidos. Dessa forma, é possível conhecer, por meio da expressão musical de cada criança - além das particularidades de sua musicalidade -, suas maneiras de ser, de sentir e de pensar, e engajá-la saudavelmente em processos amplos e diversificados de aprendizagem. Quando possibilitamos a criação coletiva de músicas inéditas pelas próprias crianças, fazemos emergir no "espaço físico" da instituição o "espaço expressivo" de seus alunos, dando em retorno uma imagem melhor qualificada de si, potencializando modalidades inéditas de diálogo e enriquecendo o campo simbólico que a todos envolve. ${ }^{9}$ Oportunizar percepções vivas de si e do "outro" através da música-criativa significa revitalizar a dimensão formadora e a dinâmica social das escolas, sobretudo nos centros urbanos desorganizados do país, tão carentes de ações educativas éticas e humanizadoras. Quando promovemos a diversificação de experiências musicais - a criação, interpretação e apresentação de músicas originais e seus usos múltiplos na instituição - promovemos também a construção de novos olhares e escutas, tanto por parte dos próprios alunos, professores e educadores, quanto da comunidade escolar e de seu entorno. Esses movimentos e percepções inovadas tornam possível atualizar, revitalizar, ressignificar os binômios "eu \& outro", "exclusão \& participação", "interior \& exterior", "ser \& estar", "criação \& educação". Além disso, é desejável que uma educação musical hoje inclua urgentemente o educador musical no processo formador, não apenas como profissional competente, porém também como ser, como indivíduo melhor trabalhado e esclarecido, a fim de que atue com conhecimento sobre os processos educativos que propõe e com consciência sobre a importância de sua representação como pessoa junto aos alunos (forma de ser, princípios, postura, atitudes, coerência, ética etc.). É desejável que uma educação musical hoje seja capaz de transgredir expectativas, mantendo tanto nos alunos quanto nos educadores

9 Desta forma, e ao mesmo tempo, se evidenciam também, no dia a dia, potenciais talentos "adormecidos", "ignorados", "desapercebidos", que em momento oportuno e em situação adequada poderiam ser melhor trabalhados ou encaminhados a instâncias de formação adequadas, pois não se busca aqui garimpar ou desenvolver talentos em vista de profissionalização. musicais a ousadia do conhecimento e a coragem de intensificar sua atenção para aprender a cada instante, atraindo-os para as vivências musicais inventivas (essas experiências novas com o mundo em movimento) sem, no entanto, desviá-los ou privá-los dos saberes existentes, nem os subjugar a qualquer tipo de saber. E se fosse perguntado por que é importante propiciar vivências musicais inventivas, a resposta seria... porque é através delas que estimulamos alternativas de expressão autênticas, propositivas e com potencial de transformação da realidade, que para acontecer de fato demandam, a cada um, estar inteiro na realidade que habita, conhecendo-a "na teoria" e com ela interagindo "na prática". E será imprescindível então avaliar qual é a transformação que desejamos, de qual mundo queremos participar da construção, bem como quais as qualidades que necessitamos cultivar em nossa própria vida - pessoal e profissional - a fim de que, coerente e responsavelmente, possamos manter esse mundo em constante aprimoramento, para nós e todos aqueles e aquelas que, talvez sem perceber o som dos passos, já caminham ao nosso lado. Enfim, é desejável que uma educação musical hoje possibilite ao "ser musical" expressar o "ser individual" (interior) de cada participante no fazer coletivo e colaborativo, e transcenda então os lugares comuns do que entendemos nesse momento por "música" e "educação". Se os educadores e educadoras musicais não perceberem o sentido maior que possui essa profissão atualmente, será, no mínimo, ilusão esperar que qualquer outra pessoa ou categoria profissional o faça por eles; e o risco da música permanecer um simples passatempo ou "brincadeira de criança" continuará rondando inúmeras classes e escolas do país. Educadores e educadoras musicais são os profissionais que têm hoje a privilegiada oportunidade de apresentar e praticar em diferentes instituições a "evolução da consciência humana através dos sons", que ordinariamente chamamos "música", em suas possibilidades infinitas. São igualmente eles - educadoras e educadores musicais - os responsáveis por cumprir a função de formação humana mais elevada pela música, e ela não é mera demanda momentânea da sociedade atual, mas uma necessidade essencial de todos os seres, desde que, há milhões de anos atrás, se começou a tecer o que chamamos "humanidade". 


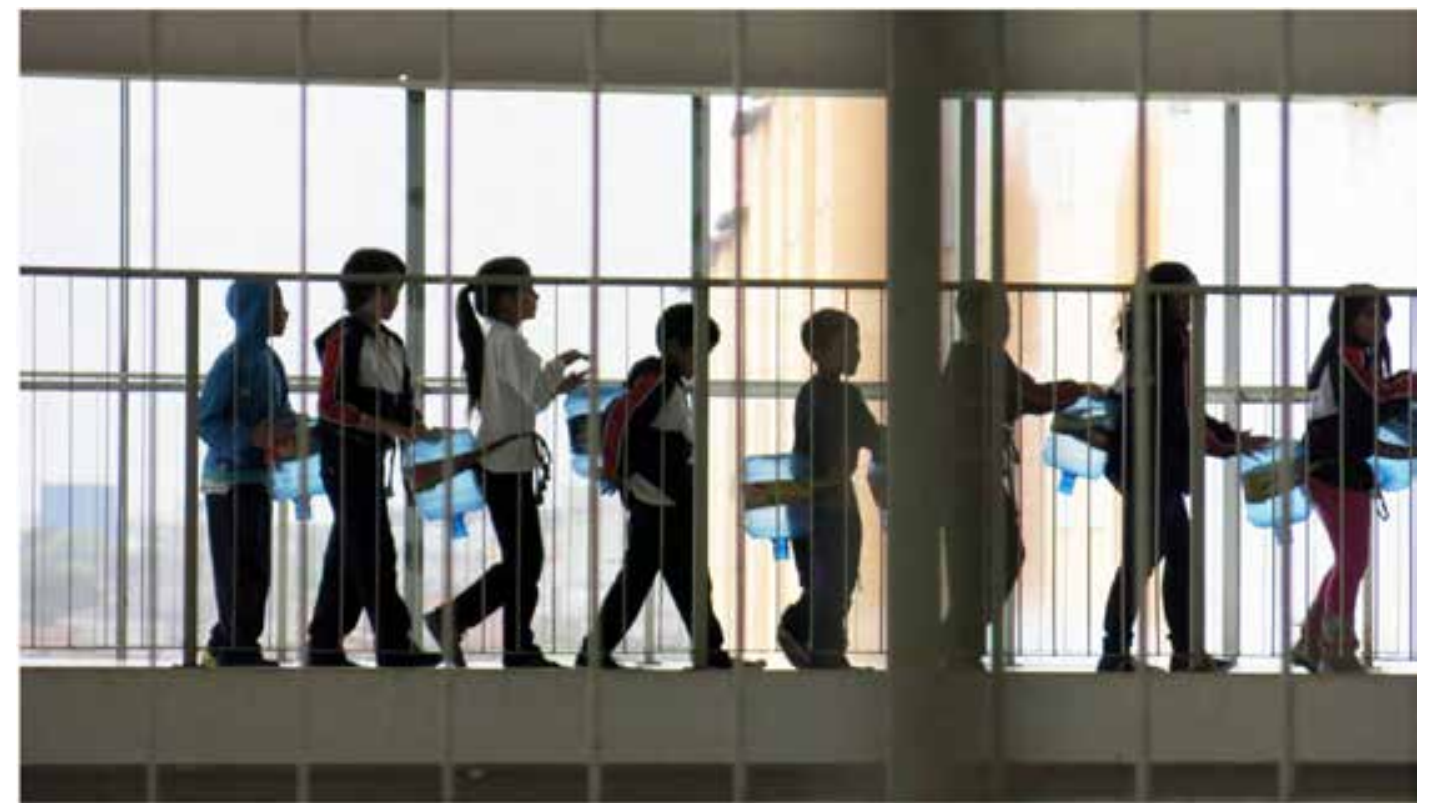

Ação musical intitulada "Centopeia", percorrendo os corredores do pátio interno do CEU Celso A. Daniel (2016).

RM - "A Música da Gente" assemelha-se a um laboratório musical e assim parece concretizar o sonho de Koellreutter (1997a, p. 57): "Deve ser a nossa Escola um laboratório, onde se cultiva o diálogo entre professores e alunos, onde se procura penetrar em tudo, elucidar e objetivar tudo que pode ser apreendido. Desejo que a nossa Escola dê a impressão de que toda a vida é uma grande experiência, um material a ser estudado. Assim a nossa Escola torna-se atual, integrada na realidade contemporânea."

Muito obrigada, Carlos Kater!

\section{Considerações finais...}

Gostaria de encerrar essa entrevista fazendo alguns comentários, a propósito do ineditismo do projeto "A Música da Gente". A história do pensamento e prática da educação musical no Brasil está pontilhada de investidas sobre uma educação pela música, uma educação musical na escola regular ou em espaços alternativos a ela. Puxo apenas alguns fios para ajudar a entender como o "A Música da Gente" responde a impasses já vividos nesta longa trajetória, como propõe respostas a situações que pareceriam paradoxais ou se mostrariam dicotô- micas, e ressaltar assim sua relevância no cenário nacional no tempo presente.

Falar sobre esse projeto é encontrar com o mesmo peso os dois termos da expressão "educação musical", garantindo rigor e qualidade para as experiências musicais nos espaços educativos. É apostar na oportunidade de formação musical de todos os sujeitos, antes que sejam divididos em classes de "músicos praticantes" e "ouvintes leigos", e apostar em um projeto sem distinção de qualidade para uns e outros educandos, desde o início. Ele não se restringe à dimensão da técnica, deixando de lado a relação dos conhecimentos com o todo da arte, da nossa existência, do meio-ambiente e da sociedade em que atuamos (KOELLREUTTER, 1997a). Ele borra as fronteiras entre aqueles voltados para o treinamento de matrizes culturais e aqueles voltados para a pesquisa e experimentação, brincando com sons inusitados e inventividade diante de um mundo que se revela sonoro-musical. Distingue-se da mera prescrição de materiais e jogos para aplicação, ou de uma pedagogia instrumental que pretende equipar o professor com um conjunto de técnicas que lhe assegure uma "boa aula". "A Música da Gente" transgride todas essas ênfases, 
produzindo um imbricado singular e um convite à invenção permanente.

Nos idos de 1940-1950, Koellreutter (1997b) defendeu um tipo novo de Escola de Música e um projeto novo para a educação musical no Brasil, onde um papel crucial era atribuído à música na humanização do processo civilizador, na interação humana, no soerguimento da personalidade, na construção de um raciocínio integrador. Nutrindo o espírito de pesquisa e investigação, a música seria um caminho para a humanização do meio ambiente e da escola, através de uma educação estética e humanista (KOELLREUTTER, 1990). A arte seria um fator preponderante de estética e de humanização do processo civilizador, um meio indispensável de educação, pelo fato de oferecer uma contribuição essencial à formação do ambiente humano. Esse seria o papel da educação pela música (KOELLREUTTER, 1997b).

O projeto de Kater parece reinventar o composto arte-educação, expressão criada pelo britânico Herbert Read (1967, p. 8): "arte" como "um processo de educação" e "educação" como "um processo artístico, de criação própria". Quando, em 1948, Augusto Rodrigues criou no Rio de Janeiro a Escolinha de Arte do Brasil, Anísio Teixeira a tomou como referência para pensar o que de mais novo e interessante poderia ser proposto como alternativa ao modelo oficial de escola (AZEVEDO, 2006). As ideias de arte-educação têm na Escolinha de Arte do Brasil seu grande centro de referência e divulgação. Nos anos 1950, essa Escolinha desenvolve as linguagens da arte de uma forma integrada, nutre o espírito de experimentação e criação, promove a autonomia dos sujeitos.

A relevância do projeto "A Música da Gente" está, a meu ver, numa tríplice dimensão. Primeiro, alcança centenas de crianças de uma escola municipal em São Bernardo do Campo (SP), e por extensão faz pensar a educação no país, tanto a que ocorre nas escolas regulares, como a que se faz através de ações da sociedade civil, em projetos sociais através da música. Fala a todos os espaços de aprendizagem. "As músicas da gente", concebidas e interpretadas, são músicas que podem estimular a criação de outras tantas, em diferentes espaços sociais.
Segundo, "A Música da Gente" investe na formação permanente, formação continuada de profissionais da educação, sejam eles os unidocentes (generalistas) ou especialistas, ou outros sujeitos comprometidos com uma educação de qualidade, agentes sociais e cuidadores. Em toda a trajetória do pensamento e prática da música na escola no Brasil, sempre um projeto de ação, abordagem metodológica ou alguma inovação vieram acompanhados de um esforço na formação de educadores. Essencial nessa formação do educador, como diz Luckesi (2000, p. 125), é uma mudança de pensamento, tendo uma "compreensão do ser humano que se desenvolve ludicamente". E essencial, também, como registra a literatura em educação, é ter uma imagem desse educador como professor-artista, isto é, que tem "uma parte de cientista" (no estudo apurado, no rigor da planificação e da avaliação) e "uma parte de artista" (como se produz o jogo pedagógico, que é sempre um jogo-em-situação) no seu trabalho docente (NÓVOA, 2004, p. 28). Ele tem um "talento artístico profissional" (SCHON, 2000, p. 17-18) e desenvolve seu fazer como uma "artistagem" (CORAZZA, 2006).

Terceiro, "A Música da Gente" deflagra questões educacionais, socioculturais e artístico-estéticas fundamentais para uma política sobre música na escola, no momento em que o país está diante da Lei 13.278, de 02 de maio de 2016 (BRASIL, 2016), em substituição à Lei 11.769 (BRASIL, 2008), que institui a obrigatoriedade do ensino de Música, Artes Visuais, Teatro e Dança na Educação Básica.

A tendência em política social durante as últimas décadas tem sido a de promover integração, inclusão e participação, essenciais à dignidade humana e ao exercício dos direitos humanos. Nesse sentido, vários são os projetos socioeducativos através da música desenvolvidos nos últimos anos no Brasil. Mas “A Música da Gente”, de Carlos Kater, é exemplo de um logos pedagógico caracterizado pela potência inventiva, que se dá a partir de uma pedagogia do afeto e de combate tanto aos modelos educacionais padronizados quanto ao enfraquecimento de esperanças. Traz uma relevante contribuição para as políticas públicas, para os discursos da Educação, incluindo as políticas de currículo, concebendo-o como um modo de 
subjetivação. Representa uma radicalidade ética, um compromisso com o humano e convida a todos nós - em especial o educador e a educadora musical contemporâneos - a participar dessa maravilhosa aventura que é a música, a criação e a educação em sentido amplo.

\section{REFERÊNCIAS}

A MÚSICA DA GENTE. Criação coletiva dos alunos da Escola Municipal de Ensino Básico Arlindo Miguel Teixeira. 2013. Disponível no Facebook do projeto: <https://www.facebook.com/amusicadagente>.

AZEVEDO, Fernando A. Sobre Augusto Rodrigues e o movimento Escolinhas de Arte. In: Programa Arte Sem Barreiras - Educaçãoarteinclusão - Caderno de textos. Rio de Janeiro, RJ: FUNARTE, 2006. p. 21-25.

BRASIL. Presidência da República. Casa Civil. Lei 11.769, de 18 de agosto de 2008. Altera a Lei no 9.394, de 20 de dezembro de 1996, Lei de Diretrizes e Bases da Educação, para dispor sobre a obrigatoriedade do ensino da música na educação básica. Brasília, DF, 2008. Disponível em: <http://www.planalto.gov.br/ccivil_03/_ato20072010/2008/lei/111769.htm>. Acesso em: 20 out. 2010.

BRASIL. Presidência da República. Casa Civil. Lei 13.278, de 02 de maio de 2016. Altera o $§ 6$ o do art. 26 da Lei no 9.394, de 20 de dezembro de 1996, que fixa as diretrizes e bases da educação nacional, referente ao ensino da arte. Brasília, DF, 2008. Disponível em: <http://www.planalto.gov.br/ccivil_03/_Ato2015-2018/2016/Lei/L13278. htm>. Acesso em: 15 mar. 2017.

CORAZZA, Sandra. Artistagens - filosofia da diferença e educação. Belo Horizonte: Autêntica, 2006.

DELEUZE, Gilles; GUATTARI, Félix. O Que é a Filosofia? 2. ed. Rio de Janeiro: Editora 34, 1997.

KATER, Carlos. O que podemos esperar da Educação Musical em projetos de ação social. Revista da ABEM, Porto Alegre, n. 10, p. 43-51, 2004.

. "Por que música na escola?": algumas reflexões. In: JORDÃO, Gisele. Et al. (Coord.). A música na escola. São Paulo: Allucci \& Associados Comunicações/MinC/3D3, 2012. p. 42-45.

KOELLREUTTER, Hans-Joachim. O espírito criador e o ensino pré-figurativo. In: KATER, Carlos (Org.). Cadernos de Estudo: Educação Musical, nº 6. São Paulo: Atravez, 1997a. p. 53-59.

O ensino da música num mundo modificado. In: KATER, Carlos (Org.). Cadernos de Estudo: Educação Musical, nº 6. São Paulo: Atravez, 1997b. p. 33-44.

Educação musical no terceiro mundo: função, problemas e possibilidades. In: KATER, Carlos (Org.).

Cadernos de Estudo: Educação Musical, n 1. São Paulo: Atravez, 1990. p. 1-8.

LUCKESI, Cipriano. Ludopedagogia: partilhando uma experiência e uma proposta. In. LUCKESI, Cipriano. (Org.). Ludopedagogia Ensaios 01: educação e ludicidade. Salvador: UFBA/FACED/Programa de Pós-Graduação em Educação, 2000. p. 119-131.

NÓVOA, Antonio. Currículo e docência: a pessoa, a partilha, a prudência. In: PEREIRA, Maria Zuleide. Et al (Org.). Currículo e contemporaneidade - questões emergentes. Campinas, SP: Alínea, 2004. p. 17-29.

READ, Herbert. La redención del robot. Buenos Aires: Paidós, 1967.

SCHÖN, Donald A. Educando o profissional reflexivo - um novo design para o ensino e a aprendizagem. Porto Alegre: Artes Médicas Sul, 2000.

SODRÉ, Muniz. Cultura, diversidade cultural e educação. In: TRINDADE, Azoilda; SANTOS, Rafael dos (Org.). Multiculturalismo: mil e uma faces da escola. 3. ed. Rio de Janeiro: DP\&A, 2002. p. 17-32. 